26 | InterAção

\title{
A COMUNIDADE ANDINA E A COOPERAÇÃO EM SEGURANÇA PARA O COMBATE AO NARCOTRÁFICO
}

\author{
Leandro Fernandes Sampaio Santos ${ }^{1}$
}

\section{Resumo}

A proposta deste trabalho é compreender a cooperação em matéria de segurança e defesa entre os países da Comunidade Andina de Nações para o combate ao narcotráfico. Pretende-se estudar o tráfico ilícito de drogas como problema para a cooperação em segurança e defesa para os países da Comunidade Andina de Nações e analisar as percepções de ameaça, os planos, as políticas e as agendas de combate ao narcotráfico na região, bem como as medidas e ações tomadas no âmbito intrabloco para conter esta modalidade de crime transnacional, partindo do pressuposto de que a problemática da guerra às drogas levou à militarização da luta contra o tráfico de substâncias ilícitas obscurecendo a fronteira entre a segurança interna e externa fazendo com que perdure o conflito na região.

Palavras-Chave: Comunidade Andina, Narcotráfico, Guerra às Drogas, Segurança Cooperativa.

\begin{abstract}
The purpose of this study is to understand cooperation on defense and security between countries of the Andean Community of $\mathrm{N}$ ations to combat drug trafficking. The intention is to study the illicit drug trafficking as a problem for cooperation in security and defense to the Andean Community of Nations and analyze threat perceptions, plans, policies and agendas to combat drug trafficking in the region, as well as the measures and actions taken in the context bloc to contain this type of transnational crime, assuming that the problem of the drug war led to the militarization of the fight against illicit substances trafficking blurring the boundary between internal and external security causing endure the conflict in the region.
\end{abstract}

1 "Mestrando em Relações Internacionais pelo Programa de Pós-Graduação em Relações Internacionais San Tiago Dantas (Unesp, Unicamp, PUC-SP), especialista em Política e Relações Internacionais pela Fundação Escola de Sociologia e Política de São Paulo - FESPSP - (2012) e em Educação e Sociedade pela Universidade da Cidade de São Paulo - UNICID - (2012) e possui licenciatura plena em História pelas Faculdades Integradas de Guarulhos - FIG - (2008). E-mail para contato: leandrof.sampaio@yahoo.com.br 
27 | InterAção

Keywords: Andean Community, Drug Trafficking, War on Drugs, Cooperative Security.

\section{INTRODUÇÃO}

Nas primeiras décadas do século XX teve início uma rígida regulação e intervenção estatal no que tange ao consumo e comercialização de drogas lícitas e ilícitas, bem como a sua tipologização tal qual conhecemos hoje em dia², incorrendo em elaboração de tratados internacionais, criação de leis específicas, aperfeiçoamento e surgimento de novos dispositivos policiais e médicos como estratégias de controle e regulamentação não apenas das drogas, mas da população. O proibicionismo deu o tom às políticas de drogas no decorrer de todo o século passado. Se por um lado crescia o número de legislações nacionais e tratados internacionais antidrogas, por outro surgiam inúmeros grupos criminosos que comercializavam e lucravam com a proibição.

A segurança internacional após a Guerra Fria passou por diferentes mudanças com o colapso da URSS e o fim do mundo bipolar. As assimetrias concernentes às capacidades militares se tornaram prementes entre os Estados Unidos e os demais países, e a crescente regionalização da segurança internacional e a necessidade de organizar coalizões regionais de segurança e defesa foram desdobramentos desse processo histórico, levando grupos de Estados situados em determinados espaços geográficos a terem objetivos militares e estratégicos inter-relacionados, tendo em vista que a segurança de um dado país está atrelada direta ou indiretamente a de seus vizinhos. Com o

\footnotetext{
2 A primeira reunião mundial sobre drogas ocorreu em 1912 para debater a questão do ópio. Após a criação da ONU, em 1945, aconteceram três convenções (1961, 1971 e 1988) sob seu auspício que deliberaram os mecanismos de controle internacional de drogas vigente até hoje.
} 
28 InterAção

fim do conflito bipolar, ganharam força no cenário internacional atores já existentes e emergiram novas organizações criminosas transterritoriais, porém com uma nova roupagem, os quais passaram a ser considerados como "ameaças" não apenas intraestatais, mas também interestatais devido a sua capacidade de articulação e atuação transnacional que repercutem em maior ou menor grau regional e mundialmente, como é o caso do tráfico de drogas.

Na Região Andina, a construção de um cenário de cooperação em matéria de segurança e defesa passa por questões complexas que geram obstáculos para a sua concretização. Essa dificuldade é associada às divergências entre os governos, aos conflitos intra e interestatais, à emergência de "novas ameaças" e sua imprecisão conceitual e à crescente militarização e securitização relacionadas às disputas, principalmente territoriais, entre os Estados. As tensões geradas por ameaças advindas do crime organizado transnacional - o narcotráfico figura entre as principais - produzem tensões na região, criando um ambiente de desconfiança e incerteza, que dificulta maior aproximação e cooperação entre os países andinos pertencentes à CAN.

A Região Andina concentra a maior produção de cocaína do mundo (UNODC, 2013) 3 e é um dos principais centros de tráfico de entorpecentes e a militarização da luta contra as drogas não tem alcançado os resultados esperados. A estratégia andina contra as drogas permitiu canalizar esforços com base no consenso e na cooperação, entretanto, a falta de efetividade dos mecanismos do bloco andino para cumprimento dos compromissos e o debate incipiente dos governos com a sociedade civil que vise uma mudança nas

\footnotetext{
3 De acordo com UNODC (2008), Em 2007 a região andina chegou a produzir cerca de 984 toneladas métricas, a maior parte era proveniente da Colômbia (600 toneladas métricas). Em 2012, no Peru, as plantações de coca chegaram a 60.400 hectares contra 48.000 hectares da Colômbia. Disponível em: http://www.unodc.org/documents/crop-monitoring/Andean_report_2008.pdf.
} 
29 | InterAção

políticas antidrogas, coloca em questão a capacidade instrumental e institucional de se criar uma comunidade de defesa e segurança cooperativa.

O presente trabalho visa debater a cooperação em matéria de segurança e defesa entre os países da Comunidade Andina de Nações para o combate ao narcotráfico no decorrer da última década. Pretende-se estudar o tráfico ilícito de drogas como problema para a cooperação em segurança e defesa para os países da Comunidade Andina de Nações e problematizar as percepções de ameaça, os planos, as políticas e as agendas de combate ao narcotráfico na região, bem como as medidas e ações tomadas no âmbito intrabloco para conter esta modalidade de crime transnacional, partindo do pressuposto de que a problemática da guerra às drogas levou à militarização da luta contra o tráfico de substâncias ilícitas obscurecendo a fronteira entre a segurança interna e externa fazendo com que perdure o conflito na região.

Para tanto, o estudo está divido em três seções: a primeira aborda brevemente a trajetória histórica da comunidade andina e as tensões existentes na região, para este intento serão utilizados a abordagem dos complexos regionais de segurança; a segunda expõe os ordenamentos institucionais e as estratégias para o combate ao tráfico de drogas no âmbito da $\mathrm{CAN}$, bem como as concepções de segurança que estão presentes em alguns dos documentos legais, no período de 2001 a 2012; por fim, será discutido a associação entre terrorismo, narcotráfico e crime organizado gerada pelos Estados Unidos na sua guerra ao terror, cujos efeitos afetaram significativamente as percepções do tráfico de drogas como ameaça à segurança dos países andinos provocando dissensões sobre a militarização da luta contra as drogas e dificultando a cooperação em matéria de segurança e defesa entre os países da CAN. 
30 | InterAção

\section{COMUNIDADE ANDINA DE NAÇÕES E O SUBCOMPLEXO REGIONAL DE SEGURANÇA}

A Comunidade Andina tem sua origem no Acordo de Cartagena, em 26 de maio de 1969, criou o Pacto Andino, recebeu depois o nome de Grupo Andino e, posteriormente, Comunidade Andina de Nações (1996). Inicialmente era formada por Colômbia, Peru, Venezuela, Equador, Bolívia e Chile. Sua característica inicial era de uma União Aduaneira e Econômica com o objetivo de limitar a penetração de capital estrangeiro. O Chile deixou o grupo em 1973, quando o Augusto Pinochet ascendeu ao poder com golpe militar. A Venezuela se retirou da CAN em 2006 por decisão do governo de Hugo Chávez. Atualmente, Bolívia, Colômbia, Equador e Peru são membros da Comunidade Andina.

De acordo com Cabral (2010, p. 08), a CAN procurou criar instituições deliberativas e decisórias com uma crescente participação da sociedade civil, tendo em vista o modelo europeu, além disso, os países andinos do bloco também buscaram aprofundar as relações comerciais entre si estimulando “o desenvolvimento econômico, a competitividade, a integração da infraestrutura e a elaboração de uma política externa comum" e busca incorporar outros elementos para agenda andina como "a discussão de medidas de caráter de inclusão social, a luta contra as drogas, o fortalecimento da democracia, defesa dos direitos humanos" e o meio ambiente. Essa incorporação de questões políticas e sociais também incorreu na abertura da agenda de segurança para novos temas objetivando estabelecer a zona de paz na região andina. 
31 InterAção

A criação e execução do Plano Colômbia nos anos 2000 geraram desconfianças e desacordos sobre a presença militar dos EUA no sul do hemisfério e a luta contra os narcotraficantes e as FARC aumentou as dissensões políticas entre a Colômbia e seus vizinhos com a invasão de fronteiras, ataques a civis e indígenas, deslocamentos forçados e com as fumigações contra as plantações de coca (TURRIAGO, 2005). Essa situação se agravou depois dos atentados de 11 de setembro de 2001 perpetrados contra os Estados Unidos, as estratégias de defesa e segurança dos norte-americanos passaram a ter um caráter mais ofensivo para responder ao terrorismo e às "novas ameaças", tais redimensionamentos repercutiram indireta e diretamente nos Andes, colocando em questão os atores regionais e seus papéis concernentes à segurança, principalmente no que tange ao combate ao terrorismo (war on terror) e o narcotráfico (war on drugs). Venezuela, Equador, Bolívia e Peru também passaram por conflitos políticos internos que se refletiram no contexto regional e internacional, provocando desequilíbrio na sub-região.

Mesmo com um relativo aumento do desenvolvimento econômico na região e avanços na participação democrática, as iniciativas institucionais e políticas são ainda incipientes para uma cooperação regional entre forças armadas ou de organizações interinstitucionais intra e interestatais. Altos índices de pobreza, desigualdade na distribuição de renda e violência urbana, riscos à estabilidade democrática, deslocamentos internos forçados somados ao crime organizado transnacional, tráfico de drogas, armas e pessoas, contrabando de precursores químicos e lavagem de dinheiro, compõe o quadro desestabilizador nos Andes, "conflitos adicionais à segurança surgem da turbulência societal, da precariedade das instituições democráticas e da tensão que caracterizou as relações civis-militares nos países da região" (BONILLA, 
32 | InterAção

s/d, p.12). As diferentes modalidades de criminalidade transnacional passaram a ser uma ameaça regional e cada vez mais os países da CAN procuram criar mecanismos de cooperação regional para o seu combate.

De acordo com Barry Buzan e Ole Wæver (2003, p. XVI), os problemas de segurança internacional têm que ser deslocados para o nível regional de análise, ou seja, um complexo regional de segurança é a interconexão dos processos de securitização e dessecuritização ${ }^{4}$ - ou os dois simultaneamente - em um conjunto de unidades que interagem entre si numa determinada região, sendo assim, os problemas de segurança estão interligados de tal maneira que as soluções para eles não se dão de forma independente, visto que "as ameaças viajam mais facilmente a curtas distâncias do que as mais longas, a distância desempenha claramente um papel na produção dos complexos regionais de segurança".

Os complexos de segurança se encontram nesse nível médio da análise entre o local e o global, o plano regional. Os sistemas de segurança regionais são definidos pelo grau das relações de poder e interações intersubjetivas de padrões de amizade e inimizade entre os atores que estão interconectados geograficamente a partir de configurações históricas e de distribuição de poder, gerando interdependência dos problemas de segurança. A variação da interdependência está relacionada à projeção de poder dos Estados em um ambiente anárquico, quanto mais fracos são os países para projetarem o seu poder, será menor o grau de interdependência, caso haja uma potência regional que domine as dinâmicas de segurança, ocorrerá o overlay, quando uma potência sobrepõe as outras dinâmicas da mesma região com seu poder. $\mathrm{Na}$ experiência andina podemos caracterizar os Estados Unidos e a sobreposição da

\footnotetext{
4 É o processo que consiste em retirar um determinado tema da esfera da segurança e colocá-lo, ou mantê-lo, dentro da esfera política, seria uma repolitização dos temas que passaram a ser tratados como problemas de segurança.
} 
33 | InterAção

sua agenda de segurança, as lutas contra o terrorismo e o tráfico de drogas são grandes exemplos desse processo.

O continente americano está divido pelos teóricos da Escola de Copenhague em dois complexos regionais de segurança (CRS), o do norte e do sul. No entanto, existem três subcomplexos no continente: o subcomplexo regional da América Central, o subcomplexo do Cone Sul e o subcomplexo Norte-Andino. Os subcomplexos regionais de segurança têm a mesma definição de um CRS e são decorrentes de maior proximidade geográfica, histórica, política e/ ou cultural de uma sub-região que representam padrões distintos de interdependência de segurança e estão inseridos dentro de um complexo regional maior (BUZAN; WÆVER, 2003, pp. 53-54). Contudo, esta proximidade não significa ausência de tensões e ameaças entre um bloco de países que compõe um complexo ou subcomplexo regional. Em uma região, ou neste "nível médio", conforme os autores, as ações e reações dos Estados podem afetar primeiro aqueles que se encontram mais próximos. Sendo assim, esta perspectiva teórica coloca a importância de pensarmos de forma regional e subregional antes de pensarmos globalmente.

Para os autores da Escola de Copenhague, os Estados de um determinado complexo de segurança constroem e compartilham as suas identidades em três níveis de variações de padrões de amizade e inimizade que se iniciam no polo negativo chegando ao polo positivo: 1) formação de conflitos; 2) regime de segurança; 3) comunidade de segurança (BUZAN; WÆVER, 2003, pp. 53-54). O primeiro padrão é caracterizado pela instabilidade relacionada às disputas, rivalidades e desconfianças. O segundo padrão ocorre quando há uma oscilação entre estabilidade e instabilidade provocada por competições entre as unidades. O terceiro padrão se forma quando ocorre a estabilidade em consequência de uma maior cooperação. Sendo assim, o subcomplexo regional 
34 | InterAção

de segurança andino seria caracterizado pelo primeiro nível, formação de conflitos, devido à instabilidade gerada nas tensões entre e dentro dos países dessa região. E o narcotráfico é um elemento fundamental para compreendermos as tensões e cooperações entre os países membros da CAN, como vimos, os problemas de segurança na contemporaneidade demandam cada vez mais soluções regionais.

\section{ORDENAMENTO INSTITUCIONAL ANDINO SOBRE O TRÁFICO DE DROGAS ILÍCITAS}

A política andina contra as drogas ilícitas se fundamenta numa percepção multidimensional do problema. O ciclo produção, tráfico e consumo de drogas é uma ameaça “à saúde e ao bem estar dos seres humanos" e "afeta as bases culturais, econômicas e sociais" dos países (SECRETARIA GENERAL DE LA CAN, 2000, p. 2). Em 2001, foi criado o Comité Ejecutivo de Coordinación em la Lucha Anti-drogas e, para conter seus efeitos negativos na região, foi instituído em 2003 o Comité Andino para El Desarollo Alternativo. Para complementar estes mecanismos institucionais, foram adotadas as decisiones instrumentos que tornam obrigatória a efetivação da luta contra as drogas nos países membros - que visam aprofundar a integração, as responsabilidades compartilhadas, a cooperação política e social.

O combate às drogas ilícitas é também um componente da Política Exterior Comum da CAN, o estabelecimento das diretrizes da política antidrogas é competência do Conselho Presidencial e a formulação da política externa e da coordenação desta política fica a cargo do Conselho de Ministros de Relações Exteriores. A Secretaria Geral executa os planos, assessora e 
35 | InterAção

coordena as atividades e as reuniões dos Estados membros e mantém as relações com organizações regionais e de cooperação.

A concepção andina de segurança foi elaborada no Compromisso de Lima, em junho de 2002, na “Carta Andina para La Paz y La Seguridad, Limitación y Control de los Gastos destinados a La Defensa Externa", a qual estabeleceu instrumentos comunitários que sustentassem uma visão comum de segurança, principalmente contra as "novas ameaças":

Estes instrumentos são marcos comunitários sólidos para enfrentar de maneira eficaz, cooperativa e solidaria os desafios colocados pelas novas ameaças à segurança - tráfico de drogas ilícitas e de armas, lavagem de dinheiro, crime organizado transnacional e terrorismo -, também devem ser encarados através de políticas que promovem maiores níveis de coesão social e de desenvolvimento na sub-região (CAN, 2006, p.7).

Este trecho que resume a visão andina de segurança apresenta uma concepção multidimensional do problema, onde as "novas ameaças" aparecem ao lado de questões políticas, sociais e econômicas, ou seja, um processo de securitização destes temas. Para entender essas diferentes dinâmicas e processos políticos, o conceito de securitização desempenha um papel fundamental para esse intento, pois a "securitização pode ser vista como uma versão extremada da politização" (BUZAN et al, 1998, p. 23).

A securitização é um ato da fala ou ato discursivo (speech act), no qual a própria enunciação é uma ação: quando um agente utiliza o termo segurança para dar um caráter de emergência para uma questão política, essa questão passa desta esfera para esfera de segurança, portanto, para proteger o objeto referente (aquilo que é percebido como objeto de uma ameaça existencial, por exemplo, a democracia ou a integridade territorial) passa a ser legítimo o uso de medidas extraordinárias de exceção para conter a potencial ameaça. 
36 | InterAção

A securitização é um processo intersubjetivo e não é um ato unilateral dos atores securitizadores, ela depende da aceitação do público, quando a audiência identifica a questão como ameaça existencial à sobrevivência de um determinado objeto de referência, o ato discursivo alcançou o seu êxito. De acordo com os autores:

Assim como na teoria dos complexos de segurança, as securitizações podem estar ligadas em conjunto positivamente (onde um grupo de atores pertencentes, ou parcialmente pertencentes, de uma mesma definição de ameaça e objeto referente), ou negativamente (onde os atores ou grupos de atores, constroem um ao outro como ameaça) no processo formando padrões potencialmente duráveis de interdependência de segurança (BUZAN; WÆVER, 2009, p.256).

No âmbito da Comunidade Andina, as securitizações estão ligadas em seu conjunto positivamente, o grupo de países desse bloco partilha da mesma definição de ameaças e objetos referentes em maior ou menor grau, o que forma uma interdependência de segurança, mas ao contrário do que afirmam os autores, não necessariamente será durável, pois o que gera tensões são as medidas extraordinárias que são empregadas para combater as ameaças existentes. A luta contra as drogas na Colômbia e no Peru tem um caráter mais militarizado em comparação com a Bolívia e o Equador.

Segundo Didier Bigo (2000), a securitização não é uma resposta à insecuritização, mas sim a capacidade de gerir e gerar a insegurança. Quando há um aumento da securitização ocorre também um aumento da insegurança. A securitização/insecuritização são práticas que atravessam tanto a esfera interna, quanto o domínio externo. $\mathrm{O}$ autor diverge da abordagem da Escola de Copenhague sobre a securitização como um simples ato discursivo exclusivo da linguagem, pois esta compreensão permite analisar apenas um lado da relação 
37 | InterAção

sem considerar as lutas de poder simbólico ${ }^{5}$. Sendo assim, a securitização "não é apenas retórica, uma ideologia que se impõe por si só”, ela é produto de um "trabalho de mobilização":

A securitização repousa sobre a capacidade dos atores para constituir estatísticas sobre os seus objetivos e sob suas próprias categorias, para colocá-los em série, para ser capaz de submetêlos a exames, aos protocolos de pesquisa, com verificações empíricas em suma, para produzir "a verdade" sobre estas declarações. Verdade que precisa ser congruente com o que é o estado atual do conhecimento sobre o mundo. Este curso é ministrado somente para os profissionais de segurança (BIGO, 2000, p. 347).

De acordo com Bigo, quem tem a capacidade de securitizar são aqueles que exercem posições de autoridade reconhecida, a posição social de quem produz determinadas declarações sobre o que é ameaça e o que se constitui como insegurança é o que da legitimidade para a securitização, apenas estes atores podem impor uma hierarquia de ameaças e de temas de segurança fazendo com que certos fenômenos sejam mais ameaçadores do que outros.

Para compreender este processo é preciso se atentar as relações de poder e concorrências existentes entre grupos sociais e dentro do campo da segurança, pois não se trata de uma estratégia unilateral de um ator isolado. É necessário abordar quem são os produtores da construção social de ameaças. Para Bigo, a partir dos aportes de Bourdieu, compreende o espaço social do campo da segurança como uma construção derivada das diferentes posições dos agentes de segurança e definida pelos diferentes lugares que cada agência ocupa no âmbito nacional e internacional.

\footnotetext{
50 poder simbólico é um poder de construção da realidade que institui e ordena o sentido de ser no mundo conformando concepções supostamente homogêneas que fazem com que seja possível a aquiescência entre os pensamentos (BOURDIEU, 2010).
} 
Os países andinos, em consonância com as determinações e resoluções de organismos internacionais, consideram a produção, tráfico e consumo de drogas ilícitas, bem como a lavagem de dinheiro, tráfico de armas e contrabando de produtos químicos utilizados na produção de drogas, como ameaças à segurança e ao desenvolvimento de seus países. Em 22 de junho de 2001, o Conselho Andino de Ministros de Relações Exteriores assinaram a Desición 505 "Plan Andino de Cooperación para la Lucha contra las Drogas Ilícitas y Delitos Conexos". O Plano Andino pretende abordar a questão das drogas ilícitas em sua totalidade abrangendo os aspectos envolvidos na produção, tráfico, consumo e delitos relacionados, tendo como princípios norteadores a "responsabilidade compartilhada" e o "pleno respeito a suas respectivas legislações e soberania" e ao Direito Internacional.

No ano de 2003, na cidade de Bogotá, os ministros de relações exteriores e de defesa da CAN6, firmaram o "Compromisso para el Fortalecimiento de La Coordinación en La lucha contra el Terrorismo y El Problema Mundial de las Drogas y lós Delitos Conexos". Este documento ratificou a adesão dos países que assinaram o compromisso às convenções internacionais contra o terrorismo, adotadas no âmbito das Nações Unidas e no âmbito hemisférico, à Convenção Interamericana contra o Terrorismo e também apoiaram a Declaração de San Salvador, a qual versa sobre o reforço da cooperação na luta contra o terrorismo, que foi adotada em 24 de janeiro de 2003 pelo Comitê Interamericano contra o Terrorismo. Nesta mesma reunião, os países membros reiteraram o repúdio a todas as formas de terrorismo e acordaram coordenar os

\footnotetext{
${ }^{6}$ Estavam presentes nesta reunião os Ministros das Relações Exteriores da Colômbia, Peru, Bolívia, Venezuela, os Ministros da Defesa da Colômbia, Peru e Equador, os Vice-ministros das Relações Exteriores do Equador e do Panamá, o Diretor Geral de Polícia do Panamá, os representantes do Ministério da Defesa da Bolívia e do Brasil, e do Secretário-Geral Tópicos América do Sul Brasil, e delegações de observadores dos Estados Unidos e da União Europeia.
} 
39 | InterAção

esforços para enfrentar os desafios postos pelo terrorismo e a sua conexão com o crime organizado transnacional em suas diferentes modalidades.

Na décima sexta reunião do Conselho Andino de Ministros de Relações Exteriores, em dezembro de 2004, na cidade peruana de Cuzco, foi adotada a Decisión 602 "Norma Andina para El Control de Sustancias Químicas que se utilizan en la fabricación ilícita de estupefacientes y sustancias psicotrópicas", tal medida, além de objetivar o controle das substâncias utilizadas na fabricação ilegal de entorpecentes e psicotrópicos, procura também proteger o território aduaneiro comunitário para impedir o desvio de importações e exportações de produtos químicos que podem ser utilizados na produção de drogas, principalmente cocaína e heroína.

Os "Princípios Orientadores y Agenda Estratégica Andina", foi um documento aprovado em 05 de fevereiro de 2010 pelo Conselho Andino de Ministros de Relações Exteriores. Na sua agenda estratégica de segurança é ressaltada a importância de "coordenar programas regionais para facilitar a aplicação da normatividade andina em matéria de luta contra o problema das drogas" e de implementar o programa antidrogas ilícitas.

No segundo semestre de 2012, os quatro países membros apresentaram a "Estratégia Andina Sobre El Problema Mundial de las Drogas 2012-2019". O programa possui 37 diretrizes gerais e inclui a elaboração de uma rede andina de prevenção, certificações regionais para os centros de tratamento de viciados e manuais sub-regionais para tratamento de precursores químicos. A estratégia objetiva também combater o narcotráfico com sanções efetivas contra as redes internacionais de tráfico de drogas e "reduzir o consumo de drogas ilegais através de fortes campanhas de conscientização dirigidas ao público consumidor". 
40 InterAção

As instituições andinas operam no combate ao tráfico de drogas em quatro frentes principais: a) o alinhamento das políticas nacionais para convergir ações para o controle da produção, erradicação dos cultivos, desenvolvimento alternativo, desmantelamento da infraestrutura de produção e transporte, combate a lavagem de dinheiro, redução da demanda; b) o avanço nas estratégias binacionais baseadas em acordos bilaterais, e comitês de bairro; c) a intensificação da estratégia andina para harmonização das legislações, capacitação de funcionários e captação de recursos de ajuda técnica e financeira internacional; d) a coordenação de posicionamentos conjuntos (CAN, 2006).

\section{A COOPERAÇÃO ANDINA PARA O COMBATE AO TRÁFICO DE DROGAS}

A produção, tráfico e consumo de drogas ilícitas permanece ainda como problemas complexos na atualidade. Suas articulações em redes difusas e suas conexões com diferentes modalidades de atividades criminosas - tráfico de armas, lavagem de dinheiro, crimes ambientais, terrorismo, etc. - estão cada vez mais estreitas e se transformam constantemente, o que os tornam mais dinâmicos e fluídos, ou seja, transnacionais, desafiando as fronteiras entre o nacional, o regional e o global, no início do século XXI.

Desde os anos de 1980, o narcotráfico foi considerado umas das principais ameaças para a segurança nacional dos Estados Unidos e se tornou um dos componentes centrais da agenda de segurança hemisférica deste país. Após os atentados de 11 de setembro, a guerra contra o terrorismo global se tornou o eixo principal da segurança e política externa norte-americana, o que levou Washington a direcionar sua atenção para outras regiões do globo, fazendo com que, neste contexto, a América Latina, principalmente a América 
41 InterAção

do Sul, deixasse de ser uma de suas prioridades. De acordo com C. A. Youngers e E. Rosin (2005), os funcionários encarregados da política externa dos Estados Unidos para região buscaram conseguir atenção e recursos colocando um leque amplo de assuntos no mesmo bojo do terrorismo e narcoterrorismo.

A (in)definição destes temas como potenciais ameaças terroristas permitiu aos Estados Unidos direcionarem os seus esforços para combater o narcotráfico e o crime organizado transnacional como uma de suas prioridades em matéria de segurança para região andina, influindo direta e indiretamente nas agendas de segurança nacionais e regionais, mais precisamente no âmbito da Comunidade Andina de Nações. Não é de hoje que assuntos como drogas, crime organizado e outras ameaças de diversos matizes, como as ambientais, se tornaram elementos discursivos justificadores para intervenções em "Estados Falidos".

A associação entre narcotráfico e terrorismo ou entre narcotráfico e guerrilha, que remetem aos anos de $1980^{7}$, se baseia na experiência colombiana a partir de uma visão estadunidense do conflito e que foi generalizada para toda região andina, fortalecendo a percepção desses temas como ameaça à segurança, o que permitiu aos governos da Comunidade Andina enfatizar a dimensão regional dessas ameaças. Esta relação nebulosa entre tráfico de drogas, terrorismo e guerrilha, impede a compreensão sobre as diferenças, particularidades e significados que existem entre esses fenômenos, seus agentes e suas atividades a nível doméstico, regional e global.

\footnotetext{
7 No início dos anos de 1980, o político norte-americano Lyndon LaRouche cunhou o termo narcoterrorismo, o qual foi elaborado para se referir a interdependência política e financeira entre Londres e Moscou nos esquemas da rede tráfico de drogas. E em 1983, o Embaixador dos Estados unidos na Colômbia, Lewis Tambs, chamou de narcoguerrilha e narcoterror as relações entre os grupos guerrilheiros colombianos e o tráfico de drogas. (RUSH, 1996)
} 
42 | InterAção

Conforme analisa Marcelo Fabián Sain (2003), abordar estes dois temas conjuntamente não apenas traz problemas epistemológicos ou analíticoconceituais, mas também político-institucionaais,

os eixos e características das políticas domésticas e internacionais em matéria de segurança dependem da dita conceitualização. Ou seja, o tratamento conceitual que faz das novas ameaças e de sua vinculação com os problemas tradicionais de segurança regional e interno de nossos países constitui a primeira etapa do processo de securitização desses assuntos e, portanto, ele depende do alcance e das particularidades das políticas de segurança a esse respeito (SAIN, 2003, p. 195).

A partir das observações de Sain, temos que definir, mesmo que provisoriamente, o que é cada um destes conceitos. A “ameaça” é um "conceito relativo a uma concepção estratégica autônoma, ela se constitui sempre na e para uma percepção", portanto,

a ameaça é essencialmente diferente do que ela manifesta: não é ela que provoca o temor, mas quem anuncia. Por isso, embora nosso inimigo possa ser o verdadeiro perigo e que possamos identificá-lo como tal, ele pode ou não, conforme as circunstâncias, nos ameaçar, ficar numa posição de ameaça, assumir uma atitude ameaçadora, etc.(...) Porém, essa atitude intimidatória, em si, não constitui para nós uma agressão, um mal, um dano, uma ofensa. A ameaça só se constitui e opera na percepção daquele que é ameaçado (SAINT-PIERRE, 2007, p. 62).

De acordo com esta abordagem de Héctor Saint-Pierre, as "novas ameaças" em si mesmas não se constituem como um perigo, pois o perigo está fora de nós e a ameaça, ao contrário, se constitui em nós, ela existe no sujeito ameaçado. As percepções de ameaças não estão mais presas às disputas e confrontos interestatais, foram redirecionadas para fatores transnacionais sem rosto, elas não advêm de atores e agentes de um governo ou Estado. $\mathrm{O}$ terrorismo, o tráfico de drogas ilícitas e o crime organizado transnacional são 
43 | InterAção

agentes centrais na emergência de novas ameaças. Esta não rostificação das "novas ameaças" dá margem para obscurecer a distinção entre segurança internacional e segurança pública, e o uso de forças armadas para combatê-las é um sinal desta confusão.

O crime organizado, segundo Sain (2003), é um empreendimento de caráter político-econômico realizado por um ou mais grupos articulados que atuam conjuntamente com o objetivo de obter, direta ou indiretamente, um benefício econômico ou outro ganho de ordem material. Portanto,

a criminalidade organizada se configura como uma empresa que supõe a colaboração entre um conjunto de pessoas que compartilham e perseguem determinados objetivos criminais e protagonizam uma série de crimes graves por um período de tempo prolongado e indefinido, usando alguma forma de disciplina e controle interno como também uma metodologia operativa combinando, em diferente medida, certas formas de violência e intimidação com modalidades diferentes de exercício de influência sobre a política, a imprensa, a administração pública e autoridades judiciais e econômicas, tudo em busca de obter ganhos e/ ou poder (SAIN, 2003, p. 196197).

O terrorismo, o crime organizado e o tráfico de drogas sofreram um processo de desterritorialização, fazendo com que esses fenômenos se transnacionalizassem e, a partir de uma percepção construída, tais fenômenos ganharam uma mesma roupagem sob o signo de "novas ameaças". As linhas que os conectam são tênues e imprecisas, e é justamente esta imprecisão que endossa o discurso securitizador e permite a criação de inúmeros mecanismos e instrumentos institucionais político-militares, viabilizando a utilização do uso da força na luta contra as drogas ilícitas.

O tráfico de drogas ilícitas na região andina não é uníssono, existe uma grande diversidade geográfica, social, cultural, política e econômica e cada país 
44 | InterAção

apresenta a sua dinâmica própria que muitas vezes se articula envolvendo nos palcos do conflito diferentes agentes de campos distintos: organizações criminosas, guerrilhas, comunidades campesinas e cocaleiras, polícias, exércitos, governos, organizações regionais e internacionais. Essa multiplicidade também se reflete nas diferentes medidas políticas e de segurança nacionais adotadas pelos países pertencentes à CAN para enfrentar o narcotráfico, que se chocam diretamente com a proposta de Política Externa de Segurança Comum Andina elaborada em 1999 e ratificada na Ata de Lima de 2000, a qual propunha ações concretas de cooperação entre os países membros para "reforçar a luta contra o problema mundial das drogas".

Para Adrián Bonilla (2003), a região andina seria um mapa composto por cenários políticos distintos integrados fragilmente, cujo processo de integração e interdependência ainda está em construção. Conforme o autor, há diferenças substanciais entre os países da região, no que concerne às sociedades nacionais e suas economias, e um fator elucidativo deste problema é o fato de que nenhum destes países tem como seu principal parceiro comercial outro país andino. No que concerne à política externa, sua agenda sempre esteve hierarquizada, cuja prioridade era o comércio exterior, mas com a implementação do Plano Colômbia e depois dos eventos de 11 de setembro, a segurança começou a disputar espaço na agenda. No decorrer das últimas décadas, a região andina experimentou trajetórias diferenciadas no que tange às políticas de combate às drogas e os marcos regulatórios nacionais das políticas de combate às drogas também são díspares entre os países andinos oscilando entre a legitimação, descriminalização e a militarização (GUSMÃO, 2009).

A CAN redefiniu sua agenda de segurança e suas estratégias incluindo, além das ameaças e atores tradicionais, também as "novas ameaças" e atores não-estatais a partir de uma concepção ampla de segurança. $\mathrm{O}$ alargamento da 
45 | InterAção

concepção de segurança nos países andinos amalgama conceitos tradicionais e não-tradicionais de segurança (BONILLA, 2003; KANNER, 2009). A concepção convencional se alicerça no monopólio legítimo da força e tem como foco os assuntos relativos à paz e a segurança enfatizando os aspectos militares, de segurança e defesa, ou seja, manter a ordem e lutar contra o crime no plano interior e defender a soberania do país no plano exterior, portanto, as ameaças devem ser combatidas militarmente como conflitos armados com inimigos internos ou externos, sejam regionais ou extrarregionais, participando da tomada de decisão somente o governo e os militares. A concepção não tradicional parte do pressuposto de que a segurança dos Estados é construída socialmente e deve estar centrada nos indivíduos e busca incorporar temas como os direitos humanos, o desenvolvimento social, a segurança ambiental, a segurança humana 8 .

Este alargamento propõe um debate sobre uma nova agenda de segurança que abrangeria conflitos econômicos, políticos e sociais, as imigrações e deslocamentos forçados, os problemas ambientais e o narcotráfico. O desafio se coloca no que tange à desmilitarização da segurança e a sua dessecuritização e repolitização, ou seja, o trato de temas de segurança no seio da esfera política, o que implicaria numa ampliação de atores que participariam no processo de tomada de decisão e na formulação de políticas públicas voltadas para estes temas.

Os governos venezuelano, boliviano e equatoriano construíram suas agendas de segurança e defesa conforme as ameaças associadas ao conflito armado colombiano e em relação às medidas tomadas pelo presidente Uribe

80 conceito de segurança humana aparece na nova Constituición de La República de Ecuador de 2008 no Art. 393 : "0 Estado deve garantir a segurança humana através de políticas e ações para garantir a coexistência pacífica entre as pessoas, promover uma cultura de paz e evitar as formas de discriminação e de violência e a prática de delitos e crimes integrados". 
46 | InterAção

para enfrentar o "narcoterrorismo" e as "novas ameaças". Estas ameaças ganharam prioridade sobre outros temas, ocasionando medidas de emergência que geraram um dilema de (in)segurança9 ${ }^{9}$, sendo que Venezuela, Equador e Bolívia têm ambições nacionais em matéria de segurança e defesa incompatíveis com as de Colômbia e Peru, que se aproximam relativamente em seus posicionamentos no combate ao narcotráfico e ao terrorismo (Plano Colômbia 1 e 2 e Plano VRAE ${ }^{10}$ ) e também em relação aos Estados Unidos com a recém criada Aliança do Pacífico (Chile, Colômbia, Estados Unidos, México e Peru).

Segundo Carlos A. Romero (2008), a Comunidade Andina de Nações está passando por uma crise institucional relacionada à desarmonia entre os modelos de desenvolvimento econômico escolhidos pelos países do bloco, bem como as divergências entre estes países concernentes à assinatura ou não do Tratado de Livre Comércio com os Estados Unidos e "pelos problemas de segurança derivados da tensão geopolítica entre Venezuela e a Colômbia, a Colômbia e o Equador e o Peru, a Bolívia e o Chile" (ROMERO, 2008, p 57).

No âmbito da CAN há uma visão institucionalizada comum de segurança, no entanto, entre os países, individualmente, não há uma visão compartilhada de segurança. O tráfico de drogas ilícitas é fator importante para verificarmos esta questão, há diferentes percepções sobre o tratamento das drogas e o uso das forças armadas para combatê-las. As discrepâncias estão relacionadas à falta de colaboração não só dos governos, mas também da

\footnotetext{
90 "dilema de insegurança" seria uma inversão da lógica realista do "dilema de segurança" de John Herz elaborada em 1950, "para quem 'os esforços de ampliação de segurança de um Estado conduzem a maior insegurança de seus vizinhos'. Em tal inversão, a ameaça passaria a ser o vizinho fraco, incapaz de controlar seu próprio território, e não o vizinho forte" (MEDEIROS FILHO, 2009, p. 219).

${ }^{10}$ E em fevereiro de 2007 foi lançado pelo presidente Alan García Pérez o Plano VRAE, em referência ao "Plano Colômbia", que tinha por objetivo garantir a paz, combater o narcotráfico e o Sendero Luminoso e promover 0 desenvolvimento socioeconômico na região. 0 vale dos rios Apurímac e Ene, conhecido como VRAE, que abrange os departamentos de Ayacucho, Cuzco e Junín no Peru.
} 
47 InterAção

própria sociedade, a qual não procura pressionar os governos a criarem mecanismos de participação democráticos e transparentes para debater as políticas públicas e as agendas de segurança nacional e regional.

O aumento recente dos índices da produção de drogas no Peru, superando a Colômbia, é um exemplo de que as ações militarizadas para combater as drogas ilícitas não estão trazendo a solução esperada e colocam sérios desafios para consolidação da confiança e da cooperação entre os países, ou mesmo para a construção de uma comunidade de segurança.

\section{CONSIDERAÇÕES FINAIS}

A Comunidade Andina passou por transformações políticas, econômicas e institucionais na última década. O tráfico de drogas ilícitas se tornou um dos grandes desafios para os países do bloco, tendo sua complexidade e crescente transnacionalização ampliado os pontos de fricção domésticos, sub-regionais, regionais e internacionais, seus efeitos são visíveis na região andina e duram décadas. As concepções e sistemas de segurança andinos sofrem com uma ausência de uma maior articulação que busque alternativas ao proibicionismo e à guerra às drogas, distinguindo o que é cada modalidade de ameaça e, consequentemente, separando o que é segurança interna e externa, as chamadas "novas ameaças" colocam desafios para os direitos humanos e para a construção da confiança, impedindo um debate sério e mais amplo sobre a fronteira obscura entre os papéis e funções das polícias e dos militares.

Os programas e mecanismos andinos para conter o tráfico de drogas aumentaram no que tange à participação da sociedade civil, diminuindo o seu viés militarizado ao menos no plano do discurso, entretanto, distante das ações 
48 | InterAção

empregadas de fato para combater o narcotráfico, o exército é frequentemente acionado para atividades de segurança interna, para não dizer permanentemente. Os avanços institucionais andinos e de seus programas para o problema mundial das drogas se esbarram em uma realidade menos colaborativa, resultado de uma deterioração da ideia de integração e de uma comunidade de segurança cooperativa.

\section{REFERÊNCIAS}

BIGO, Didier. When Two Become One: Internal and external securitisations in Europe. In: KELSTRUP, Marten; WILLIAMS, Michael C. (orgs.). International relations theory and politics of european integration. London: Routledge, 2000.

BONILHA, Adrián. Escenarios de seguridad y defensa en los países andinos. In: ROJAS ARAVENA, Francisco. (ed.) La seguridad en América Latina pos 11 de septiembre. Chile: Nueva Sociedad/ FLACSO, 2003, pp.131-156.

Una agenda de seguridad andina. S/d Disponível em:

http:// www.flacsoandes.org/internacional/publi_acade/ecuador/01bonilla_a drian.pdf Acesso em 28/10/2013

BONILLA, Adrian; PÁEZ, Alexei. Estados Unidos y La Región Andina. In:

Nueva Sociedad. Buenos Aires, 2006, pp. 126-139.

BOURDIEU, P. O poder simbólico. Rio de Janeiro: Bertrand Brasil, 2010.

BUZAN, Barry; WÆVER, Ole; WILDE, Jaap de. Securuty: a new framework analysis. London: Lynne Rienner, 1998.

BUZAN, Barry; WÆVER, Ole. Regions and Powers: the Structure of International Security. Cambridg, Cambridge University Press, 2003.

BUZAN, Barry; WÆVER, Ole. Macrosecuritisation and security constellations: reconsidering scale in securitization theory. In: Review of International Studies, V. 35, 2009, pp. 253-276. 
49 | InterAção

COMUNIDAD ANDINA DE NACIONES. Comité Ejecutivo de Coordinación em la Lucha Anti-drogas. 2001. Disponível em: www.comunidadandina.org Acesso em 25/09/2013.

COMUNIDAD ANDINA DE NACIONES. Decisión 505: Plan Andino de Cooperación para la Lucha contra las Drogas Ilícitas y Delitos Conexos, 2001. Disponível em: www.comunidadandina.org Acesso em 25/09/2013.

COMUNIDAD ANDINA DE NACIONES. Carta Andina para La Paz y La Seguridad, Limitación y Control de los Gastos destinados a La Defensa Externa. 2002. Disponível em: www.comunidadandina.org Acesso em 25/09/2013.

COMUNIDAD ANDINA DE NACIONES. Decisión 458. Lineamentos de la Política Exterior Común. 2004. Disponível em: www.comunidadandina.org Acesso em 25/09/2013.

COMUNIDAD ANDINA DE NACIONES. Compromiso para el Fortalecimiento de la Coordinación en la Lucha contra el Terrorismo y el Problema Mundial de las Drogas y los Delitos Conexos. 2003. Disponível em: www.comunidadandina.org Acesso em 25/09/2013.

COMUNIDAD ANDINA DE NACIONES. Declaración de San Francisco de Quito sobre establecimiento y desarrollo de la Zona de Paz Andina. 2004. Disponível em: www.comunidadandina.org Acesso em 26/09/2013.

COMUNIDAD ANDINA DE NACIONES. Decisión 587: Lineamientos de Política de Seguridad Externa Común. 2004. Disponível em: www.comunidadandina.org Acesso em 25/09/2013.

COMUNIDAD ANDINA DE NACIONES. Decisón 602: Norma Andina para el Control de Sustancias Químicas que se utilizan en la fabricación ilícita de estupefacientes y sustancias psicotrópicas. 2004. Disponível em: www.comunidadandina.org Acesso em 25/09/2013.

COMUNIDAD ANDINA DE NACIONES. Paz y Seguridad em la Región Andina. 2006. Disponível em: www.comunidadandina.org Acesso em 25/09/2013.

COMUNIDAD ANDINA DE NACIONES. Noticias, 22 de abril 2006. Disponível em: www.comunidadandina.org Acesso em 25/09/2013.

COMUNIDAD ANDINA DE NACIONES. Decisión 673: Programa Antidrogas Ilícitas em La Comunidad Andina. 2007. Disponível em: www.comunidadandina.org Acesso em 25/09/2013. 
50 InterAção

COMUNIDAD ANDINA DE NACIONES. Princípios Orientadores y Agenda

Estratégica Andina. 2010. Disponível em: www.comunidadandina.org Acesso em 25/09/2013.

COMUNIDAD ANDINA DE NACIONES. Estratégia Andina Sobre El

Problema Mundial de las Drogas 2012-2019. 2012. Disponível em:

www.comunidadandina.org Acesso em 25/09/2013.

GUSMÃO, Luiz A. Marcos reguladores do combate às drogas nos países andinos. In: Observador On-line, v.4, n. 12, dezembro de 2009. Disponível em: http://www.opsa.com.br/images/pdf/observador/62_observador_topico_Ob servador_v_4_n_12.pdf Acesso em 10/10/ 2013.

KANNER, Aimee. Governança e segurança na região andina. In: OLIVEIRA, Marco Aurélio G. de (org.). Segurança e governança nas Américas. Olinda, Ed. do Autor, 2009, pp. 191-207.

MEDEIROS FILHO, Oscar. Geografia política sul-americana e percepções das agências de defesa. In: SOARES, Samuel; SVARTMAN, Eduardo; D'ARAÚJO, Maria C (orgs.). Defesa, Segurança Internacional e Forças Armadas: II Encontro da ABED. Campinas: Mercado das Letras, 2009, 215-228.

ROMERO, Carlos A. A Venezuela e a Comunidade Andina de Nações In: Venezuela: uma integração complexa. São Paulo: Fundação Memorial da América Latina, 2008, pp. 43-62.

RUSH, Valerie. Colombia: To fight drugs, beat narco-terrorism, 1996.

Disponível em: http:/ / www.larouchepub.com/eiw/public/1996/eirv23n1519960405/eirv23n15-19960405_048-colombia_to_fight_drugs_beat_nar.pdf Acesso em 28/10/2013.

SAIN, Marcelo. La cooperación subregional en materia de seguridad después del 11 de septimbre. ROJAS ARAVENA, Francisco. (org.) La seguridad en América Latina pos 11 de septiembre. Chile: Nueva Sociedad/ FLACSO, 2003, pp. 191-213.

SAINT-PIERRE, Héctor Luis. As "novas ameaças" às democracias latinoamericanas: uma abordagem teórico-conceitual. In: OLIVEIRA, Eliézer Rizzo.

Segurança e defesa nacional: da competição à cooperação regional. São Paulo: Fundação Memorial da América Latina, 2007, pp. 59-81.

SECRETARIA GENERAL DE LA CAN. Comunidad Andina: acciones y resultados de la lucha contra las drogas ilícitas, 2000. Disponível em: www.comunidadandina.org Acesso em 25/09/2013. 
51 InterAção

YOUNGERS, Coletta A.; ROSIN, Eileen. Drogas y democracia em América Latina: El impacto de La política de Estados Unidos, 2005. Disponível em: http://www.wola.org/es/informes/drogas_y_democracia_en_america_latina Acesso 20/09/2013.

United Nations Office on Drugs and Crime (UNODC). Relatório Mundial Sobre Drogas, 2008. Disponivel em: http://www.unodc.org/documents/cropmonitoring/Andean_report_2008.pdf Acesso em: 10/10/2013

United Nations Office on Drugs and Crime (UNODC). Relatório Mundial Sobre Drogas, 2013. Disponível em: http://www.unodc.org/documents/cropmonitoring/Andean_report_2013.pdf Acesso em: 10/02/2014 